\title{
Guidelines for the treatment of bacterial vaginosis: focus on tinidazole
}

This article was published in the following Dove Press journal:

Therapeutics and Clinical Risk Management

19 June 2009

Number of times this article has been viewed

Laura J Dickey'

Michael D Nailor ${ }^{2,3}$

Jack D Sobel ${ }^{4}$

'Department of Pharmacy Services, Detroit Receiving Hospital, Detroit, MI, USA; '2University of Connecticut, School of Pharmacy, Storrs, CT, USA; ${ }^{3}$ Hartford Hospital, Department of Pharmacy, Hartford, CT, USA; ${ }^{4}$ Wayne State University, School of Medicine, Detroit, MI, USA
Correspondence: Jack D Sobel

Chief, Division of Infectious Diseases,

Professor of Medicine, Wayne State

University, Detroit, MI, USA

Tel + | 313745 9|3|

$\mathrm{Fax}+$ I 3 |3 9930302

Email jsobel@med.wayne.edu
Abstract: Bacterial vaginosis (BV) is a complex vaginal infection most commonly associated with women of child-bearing age. Risk factors for BV are numerous. There are currently multiple clinical and laboratory tests for diagnosis of BV, including the most commonly used diagnostic methods: Amsel's criteria or Nugent's Gram stain scale. The mainstay of BV therapy is metronidazole, but tinidazole as well as a few other agents have also been used successfully. Tinidazole is the second nitroimidazole antiprotozoal agent and a structural derivative of metronidazole. With a favorable pharmacokinetic profile and reduced side effects, tinidazole is an alternative agent for BV treatment. There are minimal head-to-head comparative data to establish tinidazole's superiority to metronidazole or other therapeutic agents. Available data suggest tinidazole has a role in special populations particularly for refractory or relapsing BV.

Keywords: bacterial vaginosis, vaginosis, tinidazole, Gardnerella

\section{Bacterial vaginosis}

Bacterial vaginosis (BV) is considered the most common cause of vaginitis in women of childbearing age. ${ }^{1}$ Previously called nonspecific vaginitis, Haemophilus vaginitis, anaerobic vaginitis, and Gardnerella-associated vaginal discharge, BV is associated with a complex change in vaginal flora. The changes in vaginal flora include decrease in Lactobacillus species number, specifically decreasing the hydrogen-peroxide producing organisms, and increase in Gardnerella vaginalis, Prevotella spp., Bacteroides spp., Mobiluncus spp., Mycoplasma hominis, peptostreptococcus and/or anaerobic gram negative rods. ${ }^{2}$

Sexual activity is associated with BV although not all patients with BV have this risk factor. ${ }^{1}$ Use of vaginal douching, intravaginal nonoxynol-9 spermicide and a new sexual partner are associated with a loss of vaginal colonization by normal flora. Use of intrauterine devices, non-White race, and prior pregnancy are additional risk factors for BV. ${ }^{1}$

\section{Symptoms of bacterial vaginosis}

The most common BV symptom is a characteristic off-white, homogenous and thin vaginal discharge that frequently smell of fish. ${ }^{4}$ There is little pruritus or inflammation associated with BV. Two different diagnostic tools are used when BV is suspected, Amsel's criteria and Nugent Gram stain score. The presence of three of the four Amsel's criteria has been considered diagnostic for BV. Those criteria are homogenous discharge, $\mathrm{pH}>4.5$, positive amine test and/or presence of clue cells 
on saline microscopy. ${ }^{4}$ Nugent and colleagues published a scoring system for the diagnosis of $\mathrm{BV}$ based on a Gram-stain vaginal smear. A score is assigned to the vaginal flora on a weighted continuum from 0 to 10 based on large Gram-positive rods, small Gram-negative or variable rods, or curved rods morphotypes. ${ }^{5}$ Culture of the discharge is not useful but molecular methods are currently being evaluated to diagnosis this condition. A DNA probe for G. vaginalis is already available and detects high numbers of $G$. vaginalis organisms only to differentiate BV from $G$. vaginalis vaginal colonization.

Targeted polymerase chain reaction (PCR) has recently been studied for detection of vaginal bacteria associated with bacterial vaginosis. As reported by Fredricks and colleagues who developed a series of taxon-directed 16S rRNA gene PCR assays for more sensitive detection of key vaginal bacteria. The goal of the research was to determine the prevalence of each species in the vagina, its association with BV, and the utility of PCR for microbiological diagnosis of BV. Seventeen targeted PCR assays were made for vaginal bacterial species and tested against 264 samples of 81 subjects with BV and 183 subjects without BV. ${ }^{3}$ Leptotrichia/Sneathia, Atopobium vaginae, Megasphaera species, and three bacteria in the order of Clostridiales are significantly associated with BV. PCR detection of either a Megasphaera species or one of the Clostridiales bacteria yielded a sensitivity of $99 \%$ and specificity of $89 \%$ for diagnosis of BV compared to the Amsel's clinical criteria and sensitivity of $96 \%$ and a specificity of $94 \%$ compared to Nugent criteria. With this study, PCR detection of one or more fastidious bacterial species has been shown to be more reliable indicator of BV than cultures for detection of bacteria, such as G. vaginalis, highlighting the potential of PCR for the diagnosis of BV. Although this novel diagnostic procedure appears to be more effective in detecting BV; it lacks practical feasibility in the clinic and will likely by used in research studies only. ${ }^{3}$ This study provided much needed information as to the microbiology of BV, opening up the opportunity for new insights into its pathogenesis.

\section{Available therapy for bacterial vaginosis}

The mainstay of BV therapy has been metronidazole, $500 \mathrm{mg}$ by mouth twice daily or $750 \mathrm{mg}$ extended release by mouth once daily for seven days. Treatment of male partners with metronidazole has not reduced the rate of recurrence among affected women. ${ }^{2}$ Alternatives to oral metronidazole include: vaginal therapies with $2 \%$ clindamycin or
$0.75 \%$ metronidazole. Recurrence within three months is common and is associated with $30 \%-40 \%$ of all cases of BV. Tinidazole, an antimicrobial agent initially used for Trichomonas vaginalis infections has also been shown to be effective for BV. ${ }^{6}$

\section{Tinidazole}

Tinidazole was recently introduced to the United States in order to combat metronidazole-resistant vaginal trichomoniasis. This agent also has other uses outside of vaginal infections such as Clostridium difficile-associated diarrhea; ${ }^{7}$ chronic refractory pouchitis; ${ }^{8}$ giardiasis; ${ }^{9}$ and treatment of Helicobacter pylori infections. ${ }^{10}$ It is the second nitroimidazole antiprotozoal agent and is a structural derivative of metronidazole by replacement of a 2-(hydroxyl)ethyl group in the 5-nitroimidazole backbone with a 2-(ethylsulfonyl)ethyl moiety. ${ }^{11}$ Tinidazole is a prodrug that is converted to its active form by reduction of its nitro group to toxic radicals via the ferredoxin-mediated electron transport. This reduction reaction causes a gradient for increased permeability of tinidazole molecules to enter the cell resulting in increased toxicity and antimicrobial activity. ${ }^{11}$

\section{Pharmacokinetics of tinidazole}

Tinidazole is available via intravenous infusion, oral, rectal, or intravaginal administration, but is currently only available orally in the United States. ${ }^{12}$ Absorption is different based on which type of administration is used, with oral administration having $>90 \%$ bioavailability. ${ }^{13}$ Rectal administration resulted in $39 \%$ bioavailability while intravaginal administration resulted in $10 \%$ bioavailability.

Approximately $12 \%$ of tinidazole is protein-bound and it diffuses into most tissues. ${ }^{13}$ Steady-state tissue site concentrations of cerebrospinal fluid (CSF), abdominal sites (such as bile, intestinal mucosa and peritoneum), gynecological sites (vaginal secretions, uterine and fallopian tubes), dental bone and saliva are similar to corresponding serum concentrations. ${ }^{13}$ Specifically, CSF penetration is excellent without inflamed meninges. ${ }^{14}$ After single intravenous infusion, tinidazole's half-life is approximately 14 hours and a volume of distribution of 39 liters, compared to metronidazole's half-life of about seven hours and volume of distribution of 46 liters. $^{14}$

Distribution and elimination of tinidazole into the human body is through first-order kinetics. When given via intravenous infusion, $37 \%$ of tinidazole dose is recovered in the urine, with $25 \%$ as unchanged drug, $10 \%$ as a glucuronide conjugate, and $2 \%$ as the 2-hydroxymethyl metabolite. ${ }^{15}$ 
Metabolism of tinidazole is via the cytochrome $\mathrm{P} 450$ $3 \mathrm{~A} 4$ and 2B6 isoenzymes, with 2B6 having a lesser effect than $3 \mathrm{~A} 4 .^{16}$

\section{Microbial spectrum of tinidazole}

Tinidazole is effective against anaerobic protozoal parasites, such as T. vaginalis, Entamoeba histolytica and Giardia duodenalis (also known as Giardia lamblia) and anaerobic bacteria, including B. fragilis, Clostridium perfringens, and Fusobacterium spp. ${ }^{17}$ Against typical vaginal flora, G. vaginalis and Lactobacillus, resistance to tinidazole is detected in $54 \%$ of G. vaginalis and $96 \%$ of Lactobacillus. There is minimal tinidazole resistance associated with Anaerococcus spp. and Prevotella spp. ${ }^{18}$ Tinidazole is dosed as a single $2 \mathrm{~g}$ dose by mouth when used for trichomoniasis and giardiasis or 500-1000 mg by mouth multiple times a day for 7-14 days when used for amebiasis. ${ }^{11}$

\section{Adverse events profile for tinidazole}

Adverse effects associated with tinidazole most commonly involve the gastrointestinal tract causing nausea, metallic taste, dyspepsia, epigastric discomfort, anorexia, and vomiting. Compared to metronidazole therapy, tinidazole is better tolerated. ${ }^{11}$ Weakness, fatigue, and malaise as well as dizziness make the central nervous system the second most common area for adverse effects. ${ }^{11}$

\section{Tinidazole use for bacterial vaginosis}

Tinidazole's use for bacterial vaginosis and efficacy comparison with other agents is limited. It was evaluated by Ekgren and colleagues to assess clinical efficacy using different dosages and duration. Tinidazole was given as a single dose and on two consecutive days for the treatment of bacterial vaginosis in this randomized, double-blind study. The three study groups included tinidazole $2 \mathrm{~g}$ as a single dose (T1) versus tinidazole $2 \mathrm{~g}$ on two consecutive days (T2) versus placebo (P). Cure was determined by the absence of clue cells or Gardnerella vaginalis and was $51 \%, 74 \%$, and $4 \%$, respectively for each study group. The difference between the placebo group and each of the two treatment groups was statistically significant $(p<0.001)$ but there was no statistically significant difference between the two tinidazole treatment groups. The number of adverse effects reported was $44 \%, 39 \%$, and $22 \%$ in the groups, respectively. The difference when compared to placebo was statistically significant for both T2 and T1 $(p<0.05)$, but not statistically significant between T2 and T1 groups. Although only a numerically higher cure rate was detected in the second day of the therapy group and approximately the same frequency of adverse events; it was concluded that the two-day regimen was more efficacious than the one-day regimen or placebo. ${ }^{19}$

Another evaluation to optimize dosing for tinidazole was studied by Livengood and colleagues. The objective of this review was to assess the effectiveness between 21 and 30 days after tinidazole administered orally $1 \mathrm{~g}$ once daily for five days versus $2 \mathrm{~g}$ once daily for two days, as well as comparing both regimens to placebo for the treatment of bacterial vaginosis. Two hundred thirty-five patients were evaluated and superior efficacy was demonstrated with both study regimens compared to placebo; with cure rates of $36.8 \%$ ( $1 \mathrm{~g}$ daily regimen), $27.4 \%$ (2 $\mathrm{g}$ daily regimen), and $5.1 \%$ (placebo), respectively. Adverse events occurred with comparable frequency in tinidazole and placebo recipients, except for dysgeusia, which was more common in both tinidazole arms, and nausea, which was more common in the $2 \mathrm{~g}$ tinidazole group. Although the tinidazole groups had more adverse events compared to placebo, the Fisher exact test gave $\mathrm{p}$-values of 0.426 and 0.113 for the $1 \mathrm{~g}$ and $2 \mathrm{~g}$ groups, respectively. Only one serious adverse event, a perineal abscess, was seen in the placebo group and the patient was withdrawn. Overall, no patient withdrew because of unacceptability of tinidazole treatment. This study supported the use of either regimen for treatment of bacterial vaginosis. ${ }^{6}$

Tinidazole has also been shown to be effective when administered intravaginally. A prospective randomized trial evaluated treatment of bacterial vaginosis with tinidazole vaginal tablets. ${ }^{20}$ It compared three regimens: (1) oral tinidazole $150 \mathrm{mg}$ twice daily for seven days, (2) same oral treatment as (1) but the partner also received $500 \mathrm{mg}$ twice daily for four days, or (3) intravaginal tinidazole $500 \mathrm{mg}$ at bedtime for 14 days. After initial randomization, patients were reassessed at one and three months. The most benefit was seen at three-month follow-up was in treatment group 3 ; where $70 \%$ of patients were asymptomatic compared to $42 \%$ and $43 \%$ in groups 1 and $2(p<0.05)$. This study also showed that intravaginal tinidazole was beneficial particularly in patients with intrauterine contraceptive devices with $80 \%$ of group 3 responding while $30 \%$ and $29 \%$ of group 1 and 2 responding. A limitation of this study was the relatively low dose of tinidazole compared to the previously discussed two studies. Assumptions on relatively efficacy between oral and vaginally administered tinidazole should not be made based on this study only.

Vutyavanich and colleagues evaluated the treatment of tinidazole in the sexual partners of females with 
bacterial vaginosis. The objective was to determine whether a single oral $2 \mathrm{~g}$ dose of tinidazole for women with clinically diagnosed bacterial vaginosis and their partners increases the cure rate as compared with the same treatment for the female patients alone. Results indicated there were no statistically significant differences in symptomatic improvement, clinical cure rates, or culture results between the two study groups. Therefore, based on this and several other studies, routine treatment is not recommended for male partners of women with bacterial vaginosis including those with recurrent disease. ${ }^{21}$

Milani and colleagues evaluated the efficacy of oral tinidazole and the use of an acidic vaginal gel compared to vaginal clindamycin alone. Sixty-four patients were included and randomized to one of two treatment groups: (1) oral tinidazole $2 \mathrm{~g}$ single dose, then after one week, acidic vaginal gel 2 g every three days for an additional three weeks versus (2) vaginal clindamycin $2 \%$ gel once daily for seven days. Results of study were two-fold; in the short term, the two regimens were equally effective, but with the additional of the acidic vaginal gel to the tinidazole regimen, the tinidazole regimen was found to result in lowering vaginal $\mathrm{pH}$ and achieved higher normalization rates in laboratory tests at zero-month follow-up. Clinical cure rate was defined as the absence of at least two of the four signs of BV, according to Amsel's criteria. Laboratory cure rate was defined as a clinical cure plus a negative result of the BV-blue (OSOM BVBlue; Genzyme Corp., Cambridge, MA, USA) and whiff test. The study concluded that treatment of BV with single oral dose tinidazole was at least as effective as the sevenday of vaginal clindamycin regimen. Since oral tinidazole has also been found to effective as a standalone agent, it is also unclear if the acidic vagina gel had a long term clinical benefit in this study. ${ }^{22}$

Another comparison of a tinidazole-containing regimen versus complementary and alternative medicine regimen was compared by Baylson and colleagues. ${ }^{23}$ The aim of this study was to compare the efficacy of Praneem, a polyherbal pessary, versus Ginlac-V pessary, a therapy containing clotrimazole, tinidazole and lactobacilli, for treatment of women with symptomatic vaginal discharge. One hundred patients were randomized to one of the two treatments groups. Overall, symptomatic treatment was seen by $72 \%$ (Praneem) versus 78\% (Ginlac-V); laboratory cure was achieved in $78 \%$ of each group, leading to the conclusion that both regimens are valid options for treatment of symptomatic vaginal discharge. A major limitation to the study was the lack of clear and microbiologic identification of the causative agent of the abnormal discharge in these women.

With regards to recurrent bacterial vaginosis, tinidazole was evaluated in a case report by Baylson and colleagues. ${ }^{23}$ The patient was a 23-year old female who had been treated previously with multiple courses of metronidazole gel $0.75 \%$ for recurrent bacterial vaginosis without successful eradication of symptoms or laboratory clearance. A regimen of oral tinidazole $500 \mathrm{mg}$ twice daily for 14 days was given and the patient's symptoms resolved and she remained asymptomatic for 10 months. Upon follow-up during the 10 month asymptomatic period, laboratory analysis, including Gram stains, revealed resolution of infection.

\section{Conclusions}

Bacterial vaginosis is a problematic disease mainly effecting sexually active females. Tinidazole is a nitroimidazole structurally related to metronidazole with some unique properties. In vitro comparison studies show similar activity between metronidazole and tinidazole against the proposed clinically relevant bacteria. Pharmacokinetically, the longer half-life of tinidazole offers some benefit in reduced dosage or frequency of administration compared to metronidazole. Another positive attribute of tinidazole compared to metronidazole is its favorable adverse event profile. However, metronidazole has remained the standard for the treatment of BV largely related to the lack of compelling head-to-head clinical comparisons demonstrating a benefit of either agent over the other and the reduced drug acquisition costs of metronidazole. Personal clinical experience and some case reports note tinidazole is an effective option in patients with refractory $\mathrm{BV}$ or recurrent $\mathrm{BV}$ and should be considered for patients with difficult to treat BV who have had multiple treatment regimens or suppressive therapy with either metronidazole or clindamycin.

\section{Disclosure}

The authors report no conflicts of interest in this work.

\section{References}

1. Sobel JD. Vaginitis. N Engl J Med. 1997;337(26):1896-1903.

2. Mandell GL, Bennett JE, Dolin R. In: Mandell GL, Bennett JE, Dolin R, editors. Mandell, Douglas, and Bennett's Principles and Practices of Infectious Diseases. 6th Ed. Philadelphia, PA: Elsevier; 2005. p. 3656.

3. Fredricks DN, Fiedler TL, Thomas KK, Oakley BB, Marrazzo JM. Targeted PCR for detection of vaginal bacteria associated with bacterial vaginosis. J Clin Microbiol. 2007;45(10):3270-3276.

4. Kasper DL, Braunwald E, Hauser S, Longo D, Jameson JL, Fauci AS, editors. Harrison's Principle of Internal Medicine. 16th Ed. New York, NY: McGraw-Hill; 2005. 
5. Boggess KA, Trevett TN, Madianos PN, et al. Use of DNA hybridization to detect vaginal pathogens associated with bacterial vaginosis among asymptomatic pregnant women. Am J Obstet Gynecol. 2005;193(3 Pt 1):752-756.

6. Livengood CH 3rd, Ferris DG, Wiesenfeld HC, et al. Effectiveness of two tinidazole regimens in treatment of bacterial vaginosis: a randomized controlled trial. Obstet Gynecol. 2007;110(2 Pt 1):302-309.

7. Stepan C, Surawicz CM. Treatment strategies for $C$. difficile associated diarrhea. Acta Gastroenterol Latinoam. 2007;37(3):183-191.

8. Shen B, Fazio VW, Remzi FH, et al. Combined ciprofloxacin and tinidazole therapy in the treatment of chronic refractory pouchitis. Dis Colon Rectum. 2007;50(4):498-508.

9. Kiser JD, Paulson CP, Brown C. Clinical inquiries. What's the most effective treatment for giardiasis? J Fam Pract. 2008;57(4):270-272.

10. Jodlowski TZ, Lam S, Ashby Jr CR. Emerging therapies for the treatment of Helicobacter pylori infections. Ann Pharmacother. 2008; 42(11):1621-1639.

11. Fung HB, Doan TL. Tinidazole: a nitroimidazole antiprotozoal agent. Clin Ther. 2005;27(12):1859-1884.

12. Mattila J, Männistö PT, Mäntylä R, Nykänen S, Lamminsivu U. Comparative pharmacokinetics of metronidazole and tinidazole as influenced by administration route. Antimicrob Agents Chemother. 1983;23(5):721-725.

13. Lamp KC, Freeman CD, Klutman NE, Lacy MK. Pharmacokinetics and pharmacodynamics of the nitroimidazole antimicrobials. Clin Pharmacokinet. 1999;36(5):353-373.

14. Jokipii AM, Myllylä VV, Hokkanen E, Jokipii L. Penetration of the blood brain barrier by metronidazole and tinidazole. J Antimicrob Chemother. 1977;3(3):239-245.
15. Wood BA, Faulkner JK, Monro AM. The pharmacokinetics, metabolism and tissue distribution of tinidazole. J Antimicrob Chemother. 1982;10(Suppl A):43-57.

16. Li XQ, Björkman A, Andersson TB, Gustafsson LL, Masimirembwa CM. Identification of human cytochrome $\mathrm{P}(450)$ s that metabolise antiparasitic drugs and predictions of in vivo drug hepatic clearance from in vitro data. Eur J Clin Pharmacol. 2003;59(5-6):429-442.

17. Bergan T, Solhaug JH, Søreide O, Leinebø O. Comparative pharmacokinetics of metronidazole and tinidazole and their tissue penetration. Scand J Gastroenterol. 1985;20(8):945-950.

18. Austin MN, Meyn LA, Hillier SL. Suspectibility of vaginal bacteria to metronidazole and tinidazole. Anaerobe. 2006;12(5-6):227-230.

19. Ekgren J, Norling BK, Degre M, Midtvedt T. Comparison of tinidazole given as a single dose and on 2 consecutive days for the treatment of nonspecific bacterial vaginosis. Gynecol Obstet Invest. 1988;26(4): 313-317.

20. Heikkinen J, Vuopala S. Anaerobic vaginosis: treatment with tinidazole vaginal tablets. Gynecol Obstet Invest. 1989;28(2):98-100.

21. Vutyavanich T, Pongsuthirak P, Vannareumol P, Ruangsri RA, Luangsook P. A randomized double-blind trial of tinidazole treatment of the sexual partners of females with bacterial vaginosis. Obstet Gynecol. 1993;82(4 Pt 1):550-554.

22. Milani M, Barcellona E, Agnello A. Efficacy of the combination of $2 \mathrm{~g}$ oral tinidazole and acidic buffering vaginal gel in comparison with vaginal clindamycin alone in bacterial vaginosis: a randomized, investigator-blinded, controlled trial. Eur J Obstet Gynecol Reprod Biol. 2003;109(1):67-71.

23. Baylson FA, Nyirjesy P, Weitz MV. Treatment of recurrent bacterial vaginosis with tinidazole. Obstet Gynecol. 2004;104(5 Pt 1):931-932.
Therapeutics and Clinical Risk Management

\section{Publish your work in this journal}

Therapeutics and Clinical Risk Management is an international, peerreviewed journal of clinical therapeutics and risk management, focusing on concise rapid reporting of clinical studies in all therapeutic areas, outcomes, safety, and programs for the effective, safe, and sustained use of medicines. This journal is indexed on PubMed Central, CAS,

\section{Dovepress}

EMBase, Scopus and the Elsevier Bibliographic databases. The manuscript management system is completely online and includes a very quick and fair peer-review system, which is all easy to use. Visit http://www.dovepress.com/testimonials.php to read real quotes from published authors.

Submit your manuscript here: http://www.dovepress.com/therapeutics-and-clinical-risk-management-journal 